\title{
The incidence of uterine abnormalities
}

\author{
${ }^{* 1}$ Constantin Toncoglaz, ${ }^{1}$ Serghei Toncoglaz, ${ }^{2}$ Alina Toncoglaz \\ ${ }^{1}$ Departament of Anatomy and Clinical Anatomy, ${ }^{2}$ Department of Obstetrics and Gynecology \\ Nicolae Testemitanu State University of Medicine and Pharmacy, Chisinau, the Republic of Moldova \\ Authors' ORCID iDs, academic degrees and contributions are available at the end of the article \\ ${ }^{*}$ Corresponding author - Constantin Toncoglaz, e-mail: toncoglazconstantin@yahoo.com \\ Manuscript received October 15, 2021; revised manuscript November 15, 2021; published online November 26, 2021
}

\begin{abstract}
Background: Congenital uterine abnormalities result from abnormal formation, fusion or resorption of the Mullerian ducts during fetal life. These abnormalities have been associated with an increased rate of miscarriage, preterm birth, and other fetal adverse outcomes.

Material and methods: Was performed a clinical observational retrospective study of uterine malformations, diagnosed in the Republic of Moldova. Pelvic MRI (1.5-3 tesla) with contrast and without were examined, from 01.01.2016 to 20.11.2016. During this time, 190 MRIs were performed according to the program, $167 \mathrm{MRIs}$ were included in the study, $23 \mathrm{MRI}$ sere excluded, having total or partial hysterectomy performed. The age of the examined persons is between 81 years and 6 months.

Results: 15 uterine malformations were detected, which represent $11.13 \%$. Among the uterine abnormalities were detected 6 cases of bicorn uterus, 3 cases of didelph uterus, 2 cases of uterine agenesis and septate uterus and one case of arcuate uterus, and unicorn.

Conclusions: In this study it was determined that the prevalence of uterine malformations in an unselected population in the Republic of Moldova is $11.13 \%$, and that of the septate uterus is $1.2 \%$, data that are similar and correspond to the international literature.

Key words: septate uterus, uterine malformation, Mullerian duct.
\end{abstract}

Cite this article

Toncoglaz C, Toncoglaz S, Toncoglaz A. The incidence of uterine abnormalities. Mold Med J. 2021;64(5):42-46. https://doi.org/10.52418/moldovanmed-j.64-5.21.08.

\section{Introduction}

The uterus is responsible for many of the most crucial steps in the process of reproduction. Sperm migration, embryo implantation, fetal nourishment, development and growth, and finally, the process of labor and birth are all reliant on the existence of a structurally normal and functionally competent uterus [1]. Malformations of female genital organs account for $4 \%$ of all congenital malformations. They are detected in $3.2 \%$ of women of reproductive age [2]. Malformations of the genitourinary system occupy the 4 th place $(9.7 \%)$ in the structure of all developmental anomalies of modern humans [3]. Congenital uterine abnormalities are a heterogeneous group of uterine configurations that may adversely affect reproductive potential. Although subtle variations can occur, the more common abnormalities fall into two broad categories of unilateral development or failure of midline fusion. These abnormalities have been well described for over a century although the mechanisms of their unfavorable impact on fertility and clinical management have not been systematically studied. Although exact aetiologies remain unclear, the association of congenital uterine abnormalities and anatomical abnormalities in other systems of mesodermal origin suggest a possible shared cause. The proposed explanations for these organizational defects have ranged from teratogenic injury to heredity. Neither has been conclusively proven [4]. Theoretically, teratogenic interference by any agent during the developmental period of 6-10 weeks of gestation could influence any of the mesodermal systems, although convincing evidence for a well-defined teratogen is lacking. Uterine abnormalities may be familiar and be associated with defects in other mesodermal-derived systems and may be part of a more complex genetic syndrome [5]. These systems include renal, alimentary, cardiac, skeletal and auditory abnormalities. Although none have been identified, this genetic hypothesis has appeal in providing an explanation to the multiple system abnormalities across several mesodermal derivatives. The appearance of these abnormalities within several families has given credibility to a genetic basis although no specific gene defect has been identified. The exact etiologies remain undefined despite attractive hypotheses. In 1962, Pendleton Tompkins suggested that these abnormalities be viewed on a spectrum from clearly normal to clearly abnormal [6]. He suggested that the case for or against intervention rested on subtle distinctions. No debate can be mustered, for example, when there is no question that a cavity is at either end of the normal-abnormal spectrum. However, debate exists over the management of the configurations in between. Subjective standards continue to be used to differentiate normal from abnormal: what may be septate 
to one examiner may be arcuate to another. To address the need for standardization and provide a basis for reliable, one-to-one comparison of outcomes, several classification schemes have been proposed since Jarcho J. suggested one of the more specific systems in $1946[7,8]$. These classifications are intended to provide a means of assessing the likely impact of a specific abnormality on reproductive outcome and the basis for deciding when and which intervention would improve outcome. Variable definitions have evolved from broadly based and nearly useless terms such as 'double uterus' or 'duplicated uterus' to more precise definitions included in the various classification schemes. For purposes of this communication, the term 'unicornuate uterus' refers to unilateral uterine development with unilateral tube and ovary. There may be an associated uterine remnant (or rudimentary horn) with variable tubal and ovarian development and location. The term 'septate uterus' refers to a division of the uterine cavity by a midline septum that variably penetrates the cavity from one to two centimeters, resulting in partial division to the entire length of the cavity or resulting in complete division and two separate cavities. The external serosal surface of the septate uterus is normal in configuration [9]. The term 'bicornuate uterus' refers to division of the uterine cavity into two separate cavities and an associated cleft in the midline fundus, resulting in two anatomically distinct structures. There are two terms used in this setting: 'bicornuate bicollis', in which the two cavities are separate divided external uterine structures that persist throughout and are associated with two cervices with a possible longitudinal vaginal septum, and 'bicornuate unicollis', which refers to a divided uterus with one cervix and persistence of the internal division through the entire cavity up to the endocervical canal (complete) or through only part of the cavity (partial). A longitudinal vaginal septum may be associated with these abnormalities and depending on clinical scenario intervention may be required, but the first attempt to classify female congenital anomalies goes back to the beginning of the 20th century; Strassmann described septate and bicornuate uterus and some subgroups of the disorders in 1907 [10]. However, the first classification system for categorization of congenital uterine malformations was that of the American Fertility Society (AFS) published in 1988, mostly based on the previous work of Buttram V.C. and Gibbons W.F. [8, 11]. Almost 15 years later, Acien P. et al. [4] proposed another option for the classification of congenital female malformations using the embryological origin as the basis of the system. A newer version of this classification has been published recently [12]. Furthermore, Oppelt P. et al. [13] published a very detailed classification system based on the Tumor Nodes Metastases (TNM) principle in oncology and known as vagina, cervix, uterus, adnexae and associated malformations (VCUAM) classification system. It is also interesting that, apart from these alternatives for the classification of the female genital malformations in general, some other subdivisions for certain categories of anomalies have been published. AFS classification received wide acceptance and it is still the most broadly used system [14].

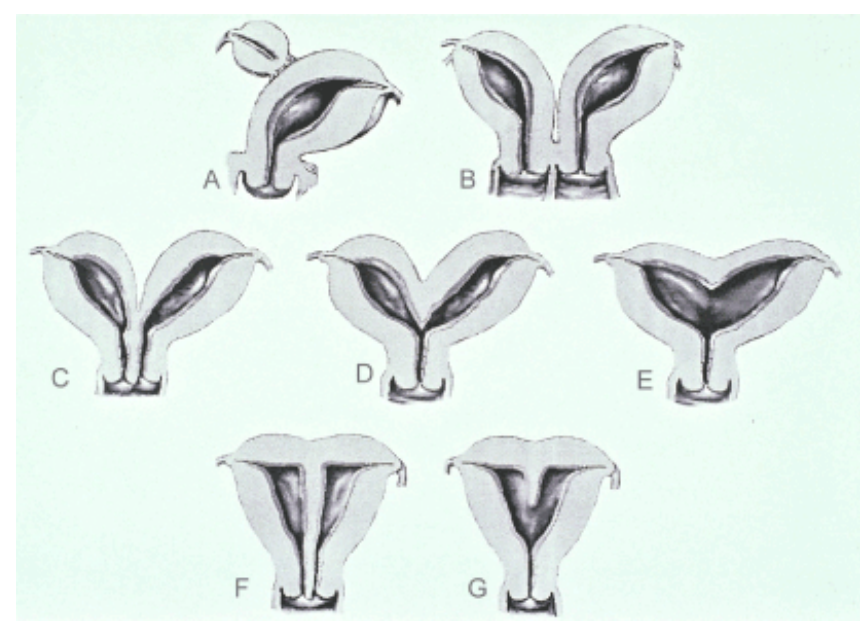

Fig. 1. Main groups of uterine anomalies.

A - Unicornuate uterus with rudimentary horn, B - Didelphic uterus, C - Complete bicornuate uterus, D - Partial bicornuate uterus, E - Arcuate uterus, F - Septate uterus, G - Subseptate uterus. Uterine agenesis and diethylstilbestrol - related T-shaped uterus are not presented [15].

Septate uterus is one of a variation of uterine abnormalities that have as their commonality a failure of midline fusion. The incidence is $5-35 \%$ in the infertile population (excluding the milder and normal variant of arcuate uterus). The identification of a septate uterus as contributing to poor reproductive outcome dates to the turn of the 20th century, with various practitioners identifying uterine duplication as contributing to first-trimester pregnancy loss. According to the recent ESHRE-ESGE classification, a septate uterus is defined as a congenital uterine anomaly with an abnormal resorption of the midline septum, a normal outline of the uterus and an internal indentation at the fundal midline exceeding $50 \%$ of the uterine wall thickness, regardless of the size of the septum [16]. Women with a septate uterus are at increased risk of miscarriage, preterm delivery, and fetal malpresentation and have lower clinical pregnancy rates [17]. In women with a septate uterus, resection of the septum is performed as standard worldwide. Observational studies suggest that surgery improves reproductive outcome in women with a septate uterus, but this has yet to be substantiated by randomised controlled trials that are currently underway $[18,19]$. The rationale behind septum resection assumes that the septum is composed of an entirely different structure than the normal uterine wall $[20,21]$. Therefore, implantation in the septum would hypothetically lead to poorer reproductive outcome in comparison to embryos that implanted in the lateral uterine wall. The foundation for this theory is meagre as knowledge about the pathophysiology of the intrauterine septum and its possible relation to impaired reproductive outcomes in women with a septate uterus is limited [22].

The unicornuate uterus is unique among Müllerian abnormalities in that the influence for abnormal development is unilateral (fig. 1) [12, 17]. The unicornuate uterus is the rarest of the uterine abnormalities accounting for $0.3-4 \%$ 
of the uterine abnormalities. This broad range is due to the varying clinical presentations and symptoms leading to evaluation. Asymptomatic patients are frequently undetected. One series of asymptomatic patients studied hysteroscopically for nonreproductive loss describes an incidence of $0.3 \%$. The incidence increases to $3.5-4 \%$ with increasingly significant history. The unicornuate uterus and rudimentary uterine horn are frequently detected as part of an evaluation for infertility and repeated pregnancy loss or the assessment of chronic and recurrent pelvic pain when an obstructive uterine horn is present [23].

Rudimentary uterine horn. The presence of a rudimentary uterine horn does not influence pregnancy outcome when the pregnancy is in the unaffected hemiunicornuate uterus [24]. Management of the uterine horn depends on the presence or absence of functioning endometrium within the horn [25]. Conventional teaching held that a rudimentary horn regardless of functionality should be removed because of an adverse influence on pregnancy outcomes when the pregnancy occurred in the normal hemiuterus. Contemporary management is more selective and based on better, outcome-related data. Excision of the uterine horn without a functioning endometrium attached to the unicornuate uterus merely to enhance obstetric outcomes is not warranted. When no functioning endometrium is demonstrated, no intervention is warranted. When functioning endometrium is present, excision should be considered particularly if there is a haematometra. The uterine horn may end bluntly or taper and end in an atretic cervical stump without a functional endocervical canal. These obstructions may also be part of a more complex and broader spectrum of anatomical changes [26].

Bicornuate uterus. A word-regarding nomenclature describing this configuration is warranted. There are three variations in this configuration and include one or two cervices (bicornuate unicollis and bicornuate bicollis, respectively) and a variable degree of cavity division (partial or complete) associated with the external configuration of two distinct structures. The term 'didelphys' is sometimes used as a generic term and refers literally to two horns. Precise nomenclature regarding this classification of uterine malformations should include a designation regarding the status of the cervix [27]. The degree of failed unification can be quite variable when there is partial fusion of the uterine horns and persistence of a cleft or division along the external contour of the uterus (bicornuate, or literally two horns). This separation may be restricted to the uterus with a single cervix (bicornuate unicollis) or extend throughout the uterus, cervix and vagina (bicornuate bicollis). These distinctions are recognized in most classification schemes and are subtle but important. The incidence of bicornuate uterine abnormalities in all categories ranges from 5 to $30 \%$, depending on history, intensity of evaluation and imaging technique used [28].

\section{Material and methods}

Was performed a clinical observational retrospective study of uterine malformations, diagnosed in the Republic of Moldova. The examination center was selected based on high access to medical data at a German Medical Center in Chisinau. Inclusion mandatory criterion was feminine gender; exclusion criterion was a person with surgical intervention on pelvic floor. Medical data of all patients with pelvic MRI (1.5-3 tesla) with contrast and without were retrospectively reviewed, from 01.01.2016 to 20.12.2016. The MRI is also associated with a high sensitivity and specificity. During this time, 190 MRIs were performed according to the program, 167 MRIs were included in the study, 23 MRIs were excluded, having total or partial hysterectomy performed. Data were collected from the Clinic of internal health informational system. The incidence of uterine malformations per 100000 of population was calculated, population data were extracted from the national bureau of statistics (the Republic of Moldova). In 2016 the national statistic bureau registered 1465175 females.

\section{Results}

The age of the examined persons in this study varies between 6 months and 81 years, with a median age of 32 years. From total of 167 investigated people 15 uterine malformations were detected, which represent $11.13 \%$. Among the uterine abnormalities were detected 2 cases of septate uterus and uterine agenesis, 6 cases of bicorn uterus, 3 cases of didelph uterus and one case of arcuate uterus, and unicorn.

The incidence of uterine malformations is 1.02 cases per 100000 population. Among disaggregated data of uterine malformations, the highest incidence was bicorn uterus with an incidence of 0.41 cases per 100000 of population. The lowest incidence was calculated for arcuate and unicorn uterus with an incidence of 0.07 cases per 100000 of population (tab. 1, fig. 2-8).

Table 1. Incidence of uterine malformation

\begin{tabular}{|c|c|c|c|}
\hline $\begin{array}{c}\text { Uterine } \\
\text { malformations }\end{array}$ & $\begin{array}{c}\text { \% from total } \\
\text { studied popula- } \\
\text { tion }\end{array}$ & Absolute & $\begin{array}{c}\text { Incidence } \\
\text { per } \\
\mathbf{1 0 0 0 0 0} \\
\text { population }\end{array}$ \\
\hline Arcuate uterus & 0.60 & 1 & 0.07 \\
\hline Unicorn uterus & 0.60 & 1 & 0.07 \\
\hline Septate uterus & 1.20 & 2 & 0.14 \\
\hline Uterine agenesis & 1.20 & 2 & 0.14 \\
\hline Didelph uterus & 1.80 & 3 & 0.20 \\
\hline Bicorn uterus & 3.59 & 6 & 0.41 \\
\hline
\end{tabular}




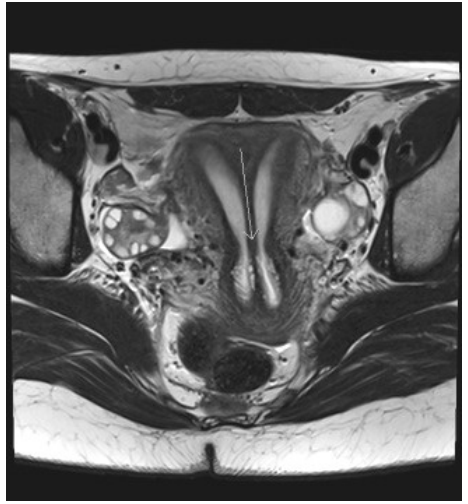

Fig. 2. Septate uterus (patient 29 years)

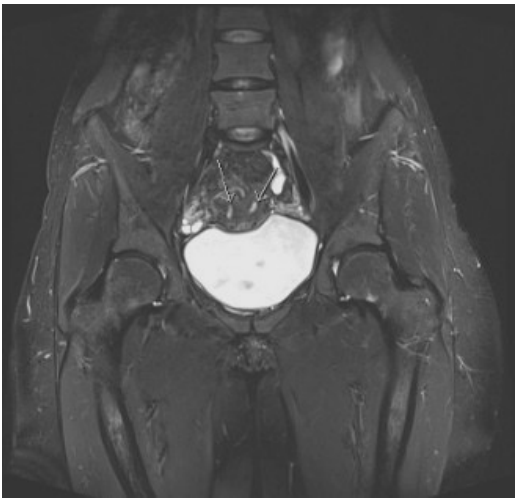

Fig. 4. Didelph uterus (patient 38 years)

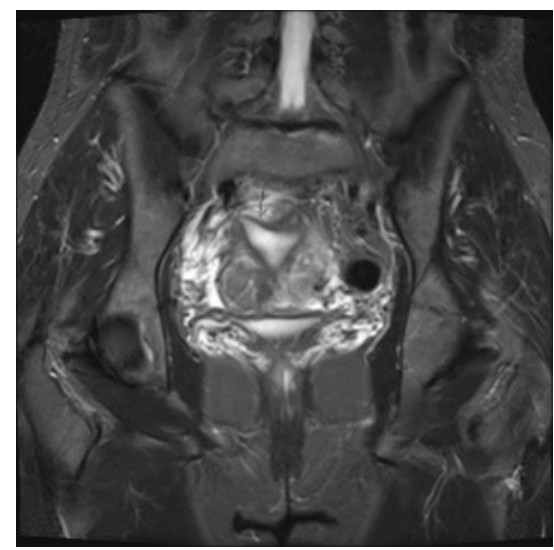

Fig. 6. Bicorn uterus (patient 25 years)

\section{Uterine malformations $11.3 \%$}

$\begin{array}{ll}\text { - Bicorn uterus } & \text { Septate uterus } \\ \text { Unicorn uterus } & \text { Didelph uterus } \\ \text { - Uterine agenesis } & \text { Arcuate uterus }\end{array}$

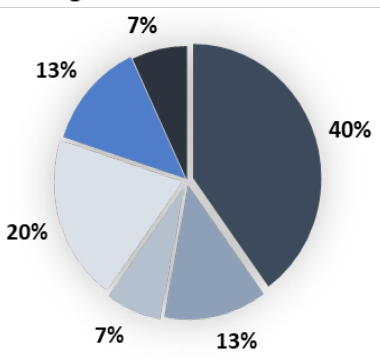

Fig. 8. Proportion of uterine malformations distributed by type

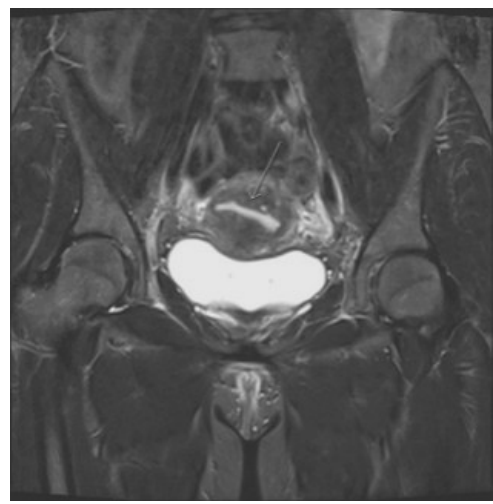

Fig. 3. Arcuate uterus (patient 32 years)

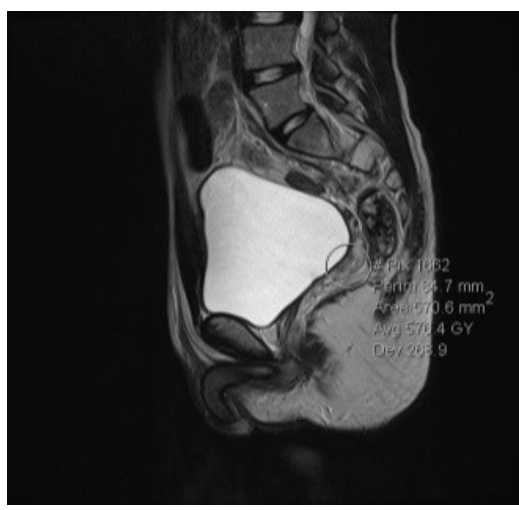

Fig. 5. Uterine agenesis (patient 1 year)

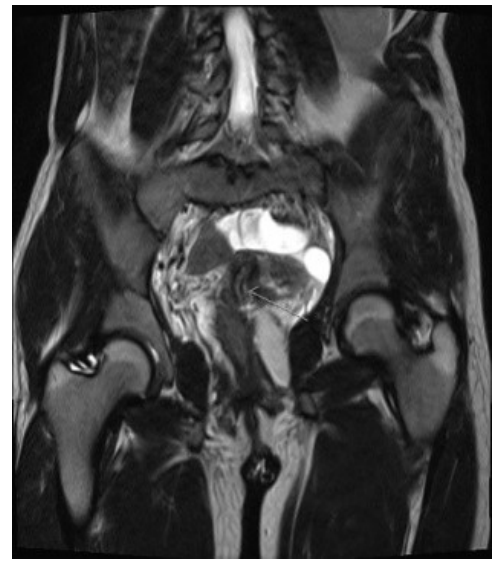

Fig. 7. Unicorn uterus (patient 42 years)

\section{Conclusions}

The incidence of septate uterus is 0.14 cases per 100 thousand of population comparing with the cumulative incidence of 1.02 cases per 100 thousand of population of uterine malformations in the Republic of Moldova. It was determined that the proportion of uterine malformations in an unselected population in the Republic of Moldova is $11.13 \%$, and that of the septate uterus is $1.2 \%$ from total investigated persons, data that are similar and correspond to the international literature. MRI seems to be a very useful diagnostic tool because it can provide detailed information about the anatomical condition of the female genital tract. 


\section{References}

1. Hassan MA, Lavery SA, Trew GH. Congenital uterine anomalies and their impact on fertility. Women's Health. 2010;6(3):443-461. doi: 10.2217/whe.10.19. PMID: 20426609.

2. Mazouni C, Girard G, Deter R, Haumonte JB, Blanc B, Bretelle F. Diagnosis of Mullerian anomalies in adults: evaluation of practice. Fertil Steril. 2008;89(1):219-222. doi: 10.1016/j.fertnstert.2007.02.044.

3. Fenton AN, Singh BP: Pregnancy associated with congenital abnormalities of the female reproductive tract. Am J Obstet Gynecol. 1952;63(4):744-755. doi: 10.1016/s0002-9378(16)38854-8.

4. Acien P, Acien M, Sanchez-Ferrer M. Complex malformations of the female genital tract, new types and revision of classifications. Hum Reprod. 2004;19(1):2377-2384. doi: 10.1093/humrep/deh423.

5. Reddy J, Laufer MR. Congenital anomalies of the female reproductive tract in a patient with Goltz syndrome. J Pediatr Adolesc Gynecol. 2009;22(4):e71-e72. doi: 10.1016/j.jpag.2008.05.009.

6. Hay D. Diagnosis and significance of minor defects of uterine abnormality in relation to pregnancy. J Obstet Gynecol Brit Emp. 1958;65(4):557582. doi: 10.1111/j.1471-0528.1958.tb08560.x.

7. Jarcho J. Malformations of the uterus. Am J Surg. 1946;71:106-166. doi: 10.1016/0002-9610(46)90190-0.

8. Buttram VC Jr, Gibbons WE. Mullerian anomalies: a proposed classification. (An analysis of 144 cases). Fertil Steril. 1979;32(1):40-46. doi: 10.1016/s0015-0282(16)44114-2.

9. Gubbini G, Di Spiezio Sardo A, Nascetti D, Marra E, Spinelli M, Greco E, et al. New outpatient subclassification system for American Fertility Society Classes V and VI uterine anomalies. J Minim Invasive Gynecol. 2009;16(5):554-561. doi: 10.1016/j.jmig.2009.06.002.

10. Agostini A, De Guibert F, Salari K, Crochet P, Bretelle F, Gamepe M. Adverse obstetric outcomes at term after hysteroscopic metroplasty. J Minim Invasive Gynecol. 2009;16(4):454-457. doi: 10.1016/j.jmig.2009.03.021.

11. The American Fertility Society classifications of adnexal adhesions, distal tubal occlusion, tubal occlusion secondary to tubal ligation, tubal pregnancies, Müllerian anomalies and intrauterine adhesions. Fertil Steril. 1988 Jun;49(6):944-55. doi: 10.1016/s0015-0282(16)59942-7.

12. Acién P, Acién MI. The history of female genital tract malformation classifications and proposal of an updated system. Hum Reprod Update. 2011 Sep-Oct;17(5):693-705. doi: 10.1093/humupd/dmr021.

13. Oppelt P, Renner SP, Brucker S, Strissel PL, Stric Oppelt PG, Doerr HG, Schott GE, Hucke J, Wallwiener D, Beckmann MW. The VCUAM (Vagina Cervix Uterus Adnex-associated Malformation) classification: a new classification for genital malformations. Fertil Steril. 2005 Nov;84(5):1493-7. doi: 10.1016/j.fertnstert.2005.05.036.

14. Grimbizis GF, Campo R, et al. Clinical approach for the classification of congenital uterine malformations. Gynecol Surg. 2012;9(2):119-129. doi:10.1007/s10397-011-0724-2.
15. Heinonen PK. Renal tract malformations associated with Müllerian duct anomalies. Clin Obstet Gynecol Reprod Med. 2018;4(1):1-5. doi: 10.15761/COGRM.1000207.

16. Grimbizis GF, Gordts S, Di Spiezio SA, Brucker S, De Angelis C, Gergolet $\mathrm{M}$, et al. The ESHRE/ESGE consensus on the classification of female genital tract congenital anomalies. Hum Reprod. 2013;28(8):2032-44. doi: 10.1093/humrep/det098.

17. Gruber AT, Schlaff WD. Pregnancy outcomes in women with bicornuate and septate uteri. Topics Obstet Gynecol. 2021;41(15):1-5. doi: 10.1097/01.PGO.0000794180.80688.17.

18. Chan YY, Jayaprakasan K, Tan A, Thornton JG, Coomarasamy A, Raine-Fenning NJ. Reproductive outcomes in women with congenital uterine anomalies: a systematic review. Ultrasound Obstet Gynecol. 2011;38(4):371-82. doi: 10.1002/uog.10056.

19. Rikken JF, Kowalik CR, Emanuel MH, Mol BW, Van der Veen F, van Wely M, et al. Septum resection for women of reproductive age with a septate uterus. Cochrane Database Syst Rev. 2017;1:Cd008576. doi: 10.1002/14651858.CD008576.pub4.

20. March CM. Hysteroscopy as an aid to diagnosis in female infertility. Clin Obstet Gynecol. 1983;26(2):302-12. doi: 10.1097/00003081-19830600000010.

21. Fayez JA. Comparison between abdominal and hysteroscopic metroplasty. Obstet Gynecol. 1986;68(3):399-403. doi: 10.1097/00006250198609000-00023.

22. Rikken JFW, Leeuwis-Fedorovich NE, Letteboer S, Emanuel MH, Limpens J, van der Veen F, Goddijn M, van Wely M. The pathophysiology of the septate uterus: a systematic review. BJOG. 2019;126(10):1192-1199. doi: 10.1111/1471-0528.15798.

23. Heinonen PK. Unicornuate uterus and rudimentary horn. Fertil Steril. 1997;68(2):224-230. doi: 10.1016/s0015-0282(97)81506-3.

24. Spitzer RF, Kives S, Allen LM. Case series of laparoscopically resected noncommunicating functional uterine horns. J Pediatr Adolesc Gynecol. 2009;22(1):e23-e28 doi: 10.1016/j.jpag.2007.12.001.

25. Sadik S, Taskin O, Sehirali S, Mendilcioglu I, et al. Complex Müllerian malformation: report of a case with a hypoplastic non-cavitated uterus and two rudimentary horns. Hum Reprod. 2002;17(5):1343-1344. doi: 10.1093/humrep/17.5.1343.

26. Shavell VI, Montgomery SE, Johnson SC, et al. Complete septate uterus, obstructed hemivagina, and ipsilateral renal anomaly: pregnancy course complicated by a rare urogenital anomaly. Arch Gynecol Obstet. 2009;280(3):449-452. doi: 10.1007/s00404-008-0919-6.

27. Alborzi S, Asadi N, Zolghadri J, Zolghadri J, Alborzi SM. Laparoscopic metroplasty in bicornuate and didelphic uteri. Fertil Steril. 2009;92(1):352-355. doi: 10.1016/j.fertnstert.2008.04.025.

28. Sinha R, Mahajan C, Hegde A, Shukla A. Laparoscopic metroplasty for bicornuate uterus. J Minim Invasive Gynecol. 2006;13(1):70-73. doi: 10.1016/j.jmig.2005.11.00

\section{Authors' ORCID iDs and academic degrees}

Constantin Toncoglaz, MD, PhD Applicant - https://orcid.org/0000-0002-7595-068X

Serghei Toncoglaz, MD, PhD Applicant - https://orcid.org/0000-0001-7103-3289

Alina Toncoglaz, MD, PhD Applicant - https://orcid.org/ 0000-0002-6852-0374

\section{Authors' contributions}

CT designed the study, conducted the laboratory work; ST drafted the first manuscript; AT interpreted the data and critically revised the manuscript. All the authors reviewed the material and approved the final version of the manuscript.

\section{Funding}

This study was supported by Nicolae Testemitanu State University of Medicine and Pharmacy. The review study was the authors' initiative.

Ethics approval and consent to participate

Agreement was obtained from the German Diagnostic Center and from patients for the use of the data.

\section{Conflict of Interests}

The authors declare no competing interests. 